\title{
Reasons for the failure of the reactor unit lining at a petrochemical plant
}

\author{
Margarita Yakovleva ${ }^{1}$, Alexey Khlystov ${ }^{1}$, Irina Frolova ${ }^{1}$, Olga Kotkova ${ }^{1}$ * \\ ${ }^{1}$ Samara State Technical University, Institute of Architecture and Civil Engineering, \\ 194, Molodogvardeyskaya St., 443001, Samara, Russia
}

\begin{abstract}
In Russia most of the thermal units in petrochemistry are still being built with the use of piece ceramic refractories. Analysis of causes of frequent destruction of thermal units lining operated in contact with a carbon-containing medium indicates a corrosive process leading to the failure of the liner material due to the formation of soot carbon by the Bell reaction. Even high-alumina cements used for synthesizing heat-resistant dry mixtures intended to work in contact with a carbon-containing medium should not contain more than $0.1 \%$ each of $\mathrm{Fe}_{2} \mathrm{O}_{3}$ and $\mathrm{SiO}_{2}$ oxides.
\end{abstract}

\section{Introduction}

Petrochemical plants are classified as hazardous production facilities and the resulting damage in the elements of technological installations may lead to a violation of the facility safety.

In this article the issue of establishing the quality of refractory lining and meeting the operating conditions by carrying out full-scale surveys was raised.

\section{Materials and methods}

Violations of the internal devices of the unit were manifested in the detachment and destruction of the internal concrete refractory lining of the reactor after reconstructive work. Visual surveys made it possible to establish the nature of the destruction (Figures 1 and 2) detected after the first start-up of the reactor, as well as to conduct instrumental and laboratory studies of selected samples of the protective lining material.

*Corresponding author: kotkovaon@yandex.ru 


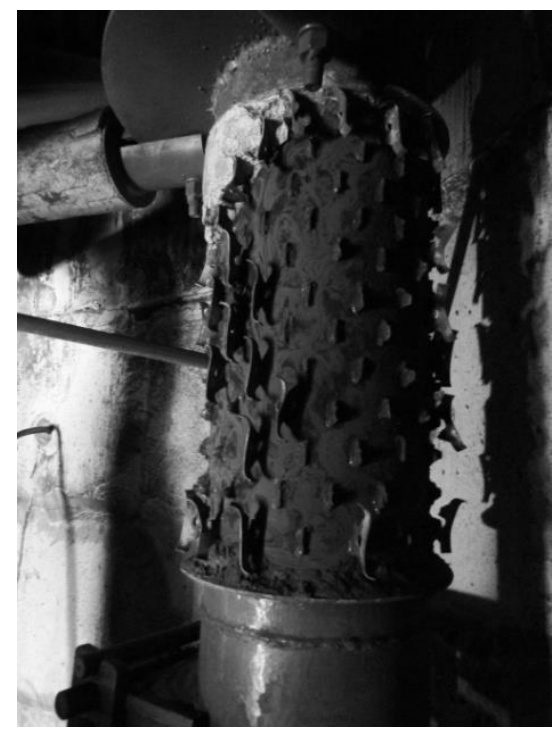

Fig. 1. Second cyclone lining concrete destruction, separation of metal anchors.

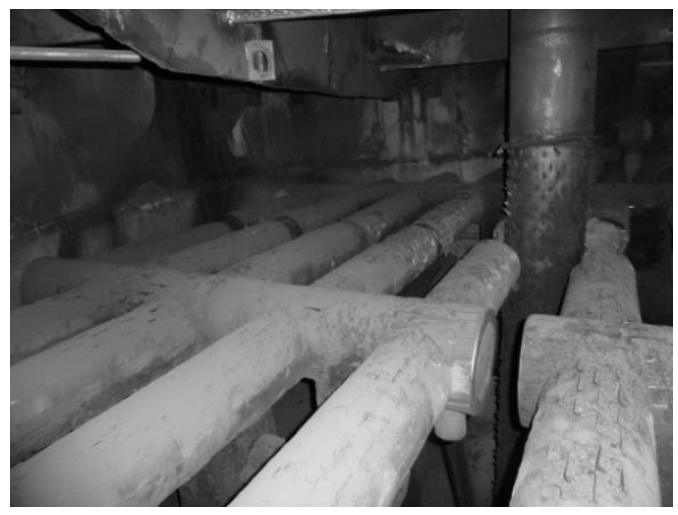

Fig. 2. Destruction of the transport line in zone 2 lining layer, concrete peeling of the horizontal grid lining.

For the analysis of possible violations of the lining installation technology, the customer presented work logs.

The nature of the visually detected damages of the liner allows us to establish the following. The inspection was carried out in accessible places of the reactor at the level of the hatches, including the transport zone in the upper, middle and lower zones of the system.

Typical for zone 1 is the vortex flow formed by the supplied catalyst stream under a pressure of $2.5 \mathrm{~atm}$ and a temperature of up to $600^{\circ} \mathrm{C}$.

Due to the dynamic effect of the vortex flow, separated at the exit by the guiding ribsplates, there may be unequal damage to the elements of the cyclone lining (Figures 3 and 4). In this area, concrete is completely destroyed in the local zones and anchor elements are partially torn off, the concrete of the lining is partially coked. 


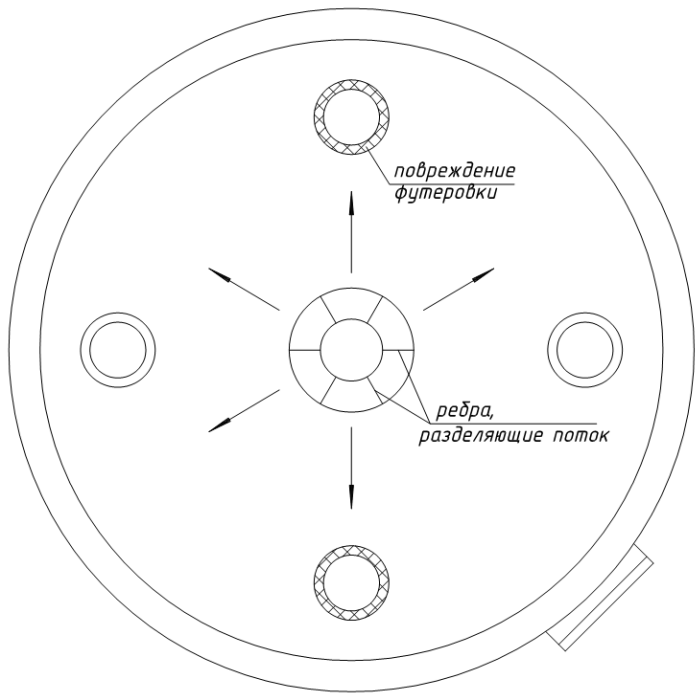

Fig. 3. Distribution of the vortex flow inside the reactor at elevations of $\sim+21,000 \div+22,000 \mathrm{~m}$.

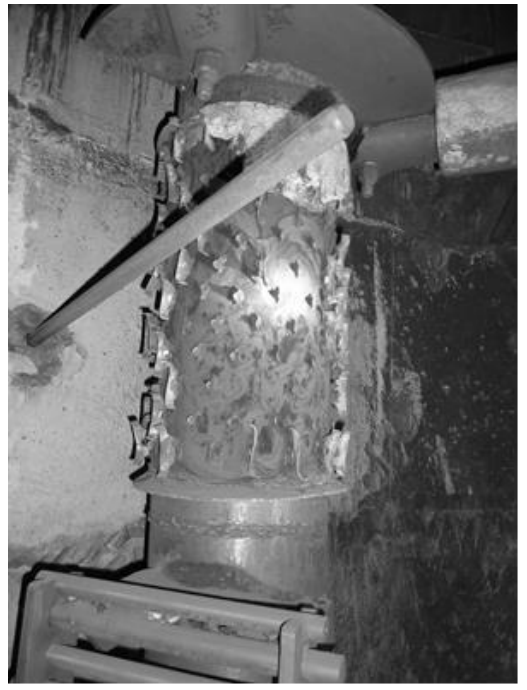

Fig. 4. Destruction of one of the cyclones concrete lining, separation of metal anchors.

In Figure 5 of the general view of the reactor zones 1 and 2 are seen where the lining is located outside the pipeline systems under the influence of hydrocarbon vapors, catalysts and a temperature of approximately $600^{\circ} \mathrm{C}$.

In Figure 6 in the lower part of the transport line zone 3 is seen. Its lining is located on the inner surface of the pipeline system and is under the influence of the regenerated catalyst.

Figures 7 and 8 show the state of the lining in the conditional zone 1, where, in addition to the medium indicated in the passport, there occurs an intensive dynamic effect of the vortex flow of the catalyst delivered under pressure from the transport system.

One of the reasons for the damage is the difference in the coefficients of thermal expansion of steel and concrete at a temperature of $600{ }^{\circ} \mathrm{C}$, which leads to disruption of the tight contact between concrete and metal [1]. The detachment of concrete from reinforcing 
elements and surface of metal elements reduces the continuity and rigidity of the lining system. The consequence was a fracture of free anchoring elements under the influence of oscillations from a mechanical vortex action.

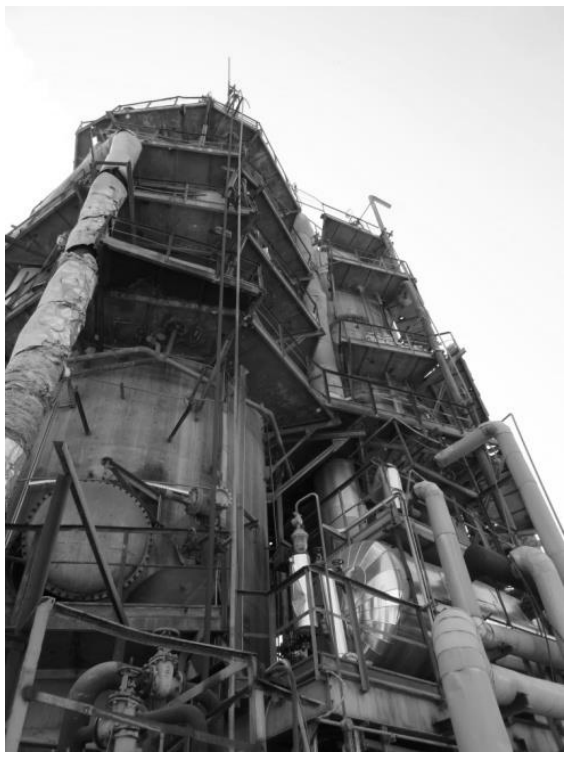

Fig. 5. Reactor unit No. 1, reactor P-5 and regenerator P-14, general view.

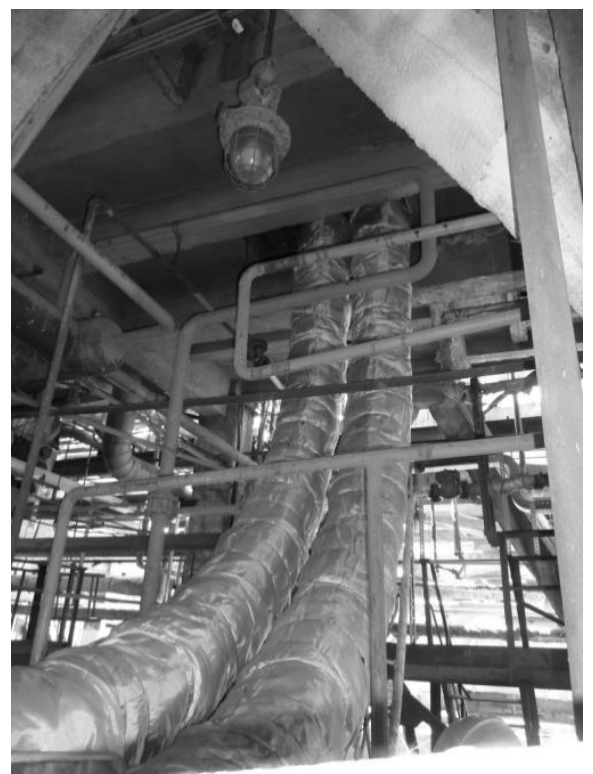

Fig. 6. General view of transport lines near the mark of $0.000 \mathrm{~m}$.

To determine the possibility of an "explosive" character of the fracture due to vaporization in the structure of concrete, the analysis of materials was carried out according to the regime of temperature rise during the start-up period of the reactor unit. The temperature regime according to the documents did not violate the regime of technological requirements that contribute to the destruction of the lining. 


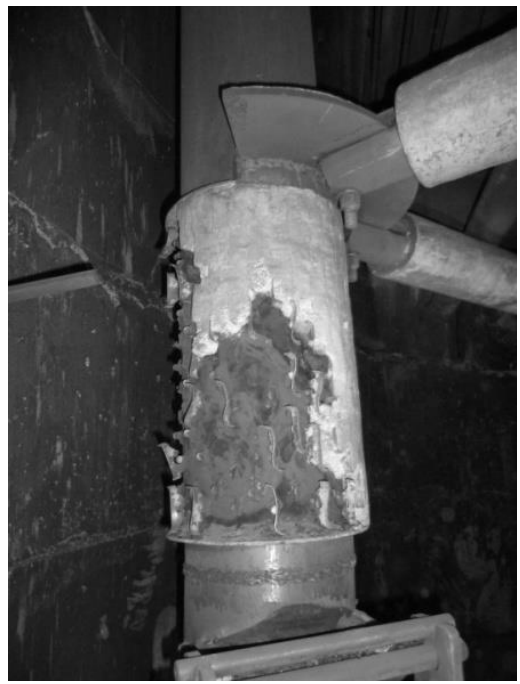

Fig. 7. Destruction of cyclone lining concrete, detachment of metal anchors.

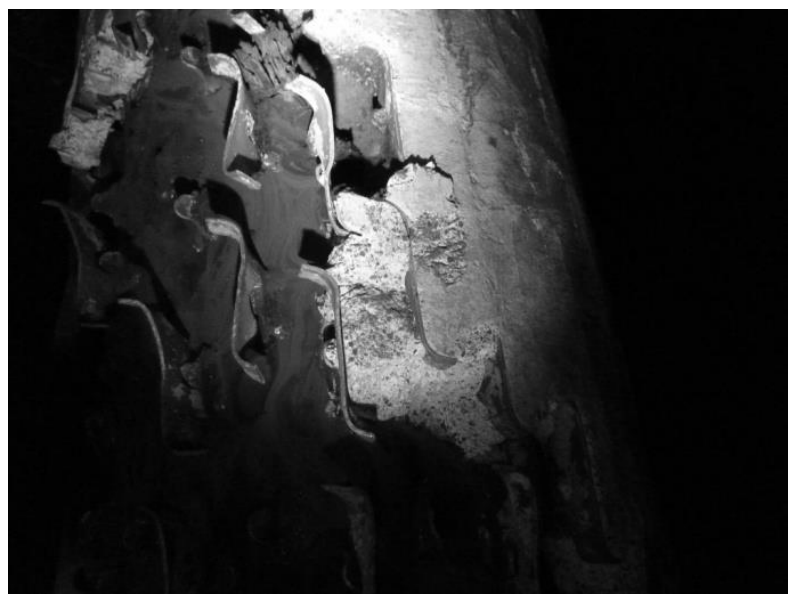

Fig. 8. Occurrence of soot carbon in the pores of concrete lining.

The carried out research revealed physical and chemical parameters of the concrete sample, formation of soot carbon on the surface and inside the lining layer; erosion of refractory materials and the disruption of the continuity of concrete lining, as well as the violation of the mating of concrete with metal equipment. The composition of the ramming paste used in the lining $[2,3]$ was analyzed.

\section{Results}

Cyclones, transport lines and other thermal installations with the operating temperature ranging from 600 to $800{ }^{\circ} \mathrm{C}$ are one of the main units of plants (reactors) for the production of hydrocarbon monomers and polymers.

Under the terms of service, the lined metal structures of these plants must be resistant to the action of a gaseous carbon-containing medium, in particular to a reducing medium (CO and $\mathrm{H}_{2}$ gases) and to the particle flux of a pulverized corundum-containing catalyst. Lining constructions for thermal petrochemical units are made mainly by applying a plastic 
concrete mix to the galvanized surface of metal structures. S-shaped spikes are made of heat-resistant steel $12 \times 18$ N10T and are welded to metal structures. Modern dry heatresistant mixtures are used as a refractory material for the formation of erosion-resistant lining, which makes it possible to obtain composites with a strength of up to 90-120 MPa.

Many petrochemical enterprises (ZAO Togliattisintez, OAO Novokuibyshevsk Petrochemical Company) supply such mixtures to Aliter-Aksi LLC established with the help of foreign partners in the Leningrad Region.

Heat-resistant mixtures, which are characterized by their high strength characteristics, contain high-alumina cement, chamotte, bauxite and corundum-containing aggregates. The durability of refractory materials in technological structures of petrochemical industry depends to a certain extent, and in some cases to a greater extent, on the composition of the gaseous medium.

When processing natural gas, as well as its combustion in thermal petrochemical plants, the content of reducing gases increases: $\mathrm{CO}, \mathrm{H}_{2}, \mathrm{CH}_{4}, \mathrm{C}_{2} \mathrm{H}_{6}$.

Hydrocarbons - methane, ethane, and, consequently, natural gas emit soot carbon in the presence of catalysts. Soot carbon is also formed according to the reaction

$$
\mathrm{CO}+\mathrm{H}_{2} \rightarrow \mathrm{C}_{\text {soot }}+\mathrm{H}_{2} \mathrm{O}
$$

Of the oxygen materials corundum refractories with a low porosity are the most erosionresistant to the action of the supportive catalyst carriers under oxidizing conditions. Corundum ceramic products possess high-erosion resistance. The wear of refractory materials under the influence of a pulverized catalyst carrier is mainly due to permanent wear and tear changes in place and during the processes of wear and tear as a result of friction of solid particles with the surface of the lining.

When choosing a refractory properties such as density, porosity, compressive strength, heat resistance are also taken into account. In the case when non-flammable, heat-resistant concrete is applied, dry mixtures on aluminous cement are developed as a refractory lining material, which allows obtaining high strength results in the early periods of hardening.

Carbon monoxide $\mathrm{CO}$ is one of the most aggressive substances with respect to refractories. Its corrosive effect consists in the reduction of refractory oxides and in the action of soot carbon.

Soot carbon emission reaction flows in the volume of the porous body (refractory) slowly and can be accelerated by the action of catalysts. The catalyst is, first of all, metallic iron. The formation of soot carbon can occur in a reactor with a reducing medium according to the reaction

$$
\mathrm{CO}+\mathrm{H}_{2} \rightarrow \mathrm{C}_{\text {soot }}+\mathrm{H}_{2} \mathrm{O}
$$

\section{Discussion}

The deposition of soot carbon in the pores of refractories leads to reactions of reducing of iron oxides to metal and the interaction of metallic iron with carbon monoxide with the formation of carbides and oxides $\left(\mathrm{Fe}_{3} \mathrm{C} ; \mathrm{FeO} ; \mathrm{Fe}_{3} \mathrm{O}_{4}\right)$. These latter reactions come with a significant increase in volume.

The increase in volume leads to colmatization of the concrete structure and partial hardening, but as the carbides and iron oxides accumulate, internal stresses and cracking of the concrete are created.

The increase in volume causes stresses in the body of the lining material, exceeding the strength, which leads to destruction (Figures 1,2). Studying the wear of refractory materials under the influence of gaseous and dust-like components, German engineers established 
that rapid breakdown of furnace lining is caused by erosion associated with high velocity of gas and dust particles contained in it [4]. However, the erosion process only rarely causes the wear of the refractory masonry.

\section{Conclusions}

Thus, it is necessary to pay attention to the chemical composition of the mixture, especially to the presence of oxides of elements with variable valency (iron oxides) [5] for lining of thermal petrochemical units in the selection of heat-resistant mixtures, in addition to high strength that provides erosion and abrasion resistance.

In this regard, for the lining of thermal petrochemical units with a possibility of a hydrocarbon medium, it is recommended to use dry heat-resistant mixtures with a minimum content of iron oxide, which has a prevailing influence in the processes of destruction of practically any refractory lining materials $[6,7]$.

\section{References}

1. A.I. Khlystov, L.S. Konnova, V.A. Shirokov, A.O. Levinkov, Scientific Survey 23, 2226 (2015)

2. M.M. Buslovich, Lining materials for electric furnaces with controlled atmospheres (Moscow, 1975)

3. I.V. Kudinov, L.S. Abisheva, A.N. Branfilyova, Urban Construction and Architecture 3, 6-10 (2014)

4. A.I. Khlystov, Increasing the efficiency and improving the quality of refractory lining materials ( Samara State University of Architecture and Civil Engineering, Samara, 2004)

5. A.M. Cherepanov, S.G. Tresvyatskiy, High-refractory materials and products made of oxides (Moscow, 1964)

6. V.I. Krayukhin, O.P. Khomyakova, N.V. Khayuk, Urban Construction and Architecture 1, 78-84 (2012)

7. A. Frolov, I. Frolova, O. Kotkova, MATEC Web Conf. 86, 02007 (2016) 